\title{
Awareness, Perception and Use of Instagram's Anti-Bullying Restrict Feature among University Undergraduates in South-East Nigeria
}

\author{
CORNELIUS AGHADIEGWU UKWUEZE, Ph.D \\ Associate Professor, Department of Mass Communication, NnamdiAzikiwe University, Awka \\ UCHECHI NKAMA EZE \\ Department of Mass Communication, NnamdiAzikiwe University, Awka
}

\begin{abstract}
Blocking a social media platform account that is posting abusive content may simply drive the bully to create a new account after the first one is blocked. Therefore, blocking is not always the ideal way to prevent problematic comments and messages from being directed at an account. The Instagram's anti bullying restrict feature is a solid alternative that enables users to instead limit an unwanted account in a way that doesn't alert the bully. This study investigated the awareness, perception and use of Instagram's anti-bullying restrict feature among university undergraduates in south-east Nigeria. The study was anchored on the Protection Motivation Theory and the Uses and Gratifications Theory and likewise adopted the mixed methods approach involving Survey and Focus Group Discussion (FGD). A total of 500 respondents were chosen using the multi-stage approach while 18 respondents were purposively selected for three FGD sessions; six discussants per session. Findings showed that there was low awareness of Instagram's anti-bullying restrict feature among university undergraduates in the South-East Nigeria. Similarly, it was found that there was generally poor use of Instagram's anti-bullying feature among the undergraduates. The findings also revealed that awareness and previous experiences are major factors influencing the use of Instagram's anti-bullying restrict feature. The study thererefore recommended that effort should be made to create awareness and provide information on the use of Instagram's anti bullying restrict feature to young people where they can easily see or read them.
\end{abstract}

Keywords: Awareness, Perception, Use, Instagram, Cyberbullying, Restrict, Feature, Undergraduates DOI: $10.7176 / \mathrm{NMMC} / 100-03$

Publication date: January $31^{\text {st }} 2022$

\section{INTRODUCTION}

Communication, like every other activity of humans, is naturally interconnected with other facets of social life which it influences and is also influenced by them (Adetimirin, 2014; Qayyum, Alharbi \& Alamri, 2016). Social networks such as Facebook, Twitter, My Space, Instagram, and YouTube have become a part of us, with the ever increase in the growth of activities that can be carried out on the Internet. Social media has helped maintain existing relationship, create new ones, keeping in touch with loved ones (family, friends and relatives), and also for academic purposes (Subrahmanyam, Reich, Waechter\& Espinoza, 2008; Salvation \& Adzharuddin, 2014). One major outcome of the increasing use of ICT is bullying via electronic devices, termed cyber bullying. Some persons use the information and photos gotten from the Internet to harm others, either as a joke or for other purposes. Therefore, using the Internet not only has many unquestionable advantages but also severe risks (Carr 2010; Holfeld \& Grabe 2012).

In Nigeria, cyber bullying is a worrisome issue with negative implication on psychological well-being of youths. Though there are some established laws and policies to help in the reduction of cyber bullying yet the greatest challenge is the problem of implementation which has resulted to individuals dying silently. Several studies such as Notar and Padget, (2013); Hertz and Wright, (2013) have discovered that cyber bullying has detrimental effects on psychological well-being of youths.

Instagram ranking the fourth most popular social media site (Internet World Stat, 2021) have worked on developing ways for its user's to fight cyber bullying by themselves hence the introduction of the anti-bullying restrict feature. Consequently, given that social media has turned into an important part of university undergraduates lives, as students are heavily engaged in social networking and exposed to cyber bullying, it is essential to learn more about how the Instagram's anti-bullying restrict feature is perceived and used among university undergraduates in South-East Nigeria.

\section{STATEMENT OF THE PROBLEM}

Cyber bullying has gained considerable ground in recent times, particularly amongst university undergraduates. As the use of social media increases geometrically, the exposure of university undergraduates to online bullying could become high. Thus, social media bullying is fast replacing the already well-known type of bullying called 
physical bullying, like face-to-face encounters, physical combats, and exchange of fists, amongst others.

Instagram's anonymous profile tools has increased the act of bullying among its users. Blocking an account that is posting abusive content may simply drive the bully to create a new account after the first one is blocked. Therefore, blocking is not always the ideal way to prevent problematic comments and messages from being directed at an account. Instagram knows it has a bullying problem and is doing something about it. Hence, the anti-bullying restrict feature is a solid alternative that enables users to instead limit an unwanted account in a way that doesn't alert the bully. However, cyber-bullying often does not stop automatically but is subject to a nexus of intervening variables. Consequently, the effects of the Instagram's anti-bullying restrict feature on University Undergraduates remains problematic to predict. The foregoing problem necessitated this study.

In order to assist university undergraduates in the South-East to overcome the sensitive position that Instagram occupy in their day to day communication, no known attempt has been made, locally, to investigate, the impact of the awareness, perception and use of Instagram's Anti-Bullying Restrict Feature among University Undergraduates in South-East, Nigeria. Moreover, despite the huge amount of fund spent on curbing cybercrimes, nobody seems locally to be interested in evaluating the newly introduced anti-bullying restrict feature. This proposed research therefore, intends to fill that intellectual gap.

\section{OBJECTIVES OF THE STUDY}

The general purpose of this study was to examine the awareness, perception and use of Instagram's anti-bullying restrict feature among university undergraduates in South-East, Nigeria. The specific objectives of this were to:

1. Determine the extent university undergraduates in South-East Nigeria are aware of Instagram's anti-bullying restrict feature.

2. Ascertain the perception of the undergraduates on Instagram's anti-bullying restrict feature.

3. Determine the extent the undergraduates use Instagram's anti-bullying restrict feature.

4. Find out the factors that influence the undergraduates use of anti-bullying restrict feature.

\section{RESEARCH QUESTIONS}

In line with objectives, following research questions were formulated:

1. To what extent are university undergraduates in South-East Nigeria aware of Instagram's antibullying restrict feature?

2. What is the perception of the undergraduates on Instagram's anti-bullying restrict feature?

3. To what extent does the undergraduates use Instagram's anti-bullying restrict feature?

4. What factors influence the undergraduates' use of anti-bullying restrict feature?

\section{SIGNIFICANCE OF THE STUDY}

This study is of fundamental significance to the university undergraduates by providing them with knowledge on how the use of the anti-bullying restrict feature can protect them online as well as help build healthy online relationships.

It will also be of importance to the academic sector especially scholars in the field of advertising, public relations, political communication and marketing communication amongst others who want to know the effect that a better coordinated social media restrict feature will have on an organization's marketing objectives, consumers' patronage, branding and image building/making.

The study would further enlighten the students, parents, teachers and the entire public on the use of Instagram's anti-bullying restrict feature. Thus, individual and the public at large would benefit from the recommendations of the study which will enable them to play key roles to safeguard themselves from cyber bullying.

Finally, this research will therefore, intend to fill that gap and show the strategic importance of the awareness, perception and use of Instagram's anti-bullying restrict feature and the immense inherent benefits which university undergraduate Instagram users stand to gain by its usage.

\section{SCOPE OF THE STUDY}

The focus of the study was the awareness, perception and use of Instagram's Anti-Bullying Restrict Feature Among University Undergraduates in South-East Nigeria. Hence, the study was strictly on the newly introduced Instagram's anti-bullying restrict feature without delving into other concerns. The study was also geographically focused on university undergraduates in South-East part of Nigeria for primary data collection. The rationale behind studying this age group and geographical area is because in Nigeria most of the previous studies in the area studied younger children (adolescents) in primary and secondary schools and the South-West part of Nigeria.

There is a need to study older ones (university undergraduates) because previous researchers (e.g., Odora \& Matoti, 2015; Okoiye, Nwoga \& Onah, 2015; Smith, Mahdavi, Carvalho, Fisher, Russell \&Tippett. 2008; Walrave\&Heriman, 2011) reported that the perpetration of cyber bullying increases with age. Therefore, the 
findings discovered from studying this age group and geographical area will help to design appropriate intervention strategies that will be targeted to this age group and geographical area and that will help to reduce the incidence of it to its barest minimum.

\section{LITERATUREREVIEW}

\section{Conceptualizing Instagram}

Instagram is a popular photo (and video) capturing and sharing mobile application, with more than 150 million of registered users since its launch in October 2010. It offers its users a unique way to post pictures and videos using their smart phones, apply different manipulation tools -16 filters - in order to transform the appearance of an image, and share them instantly on multiple platforms (e.g., Twitter). In addition to the user's Instagram page, it also allows users to add captions, hashtags using the \# symbol to describe the pictures and videos, and tag or mention other users by using. the @ symbol (which effectively creates a link from their posts to the referenced user's account) before posting them. In addition to its photo capturing and manipulation functions, Instagram also provides similar social connectivity as Twitter that allows a user to follow any number of other users, called "friends". On the other hand, the users following an Instagram user are called "followers". Instagram's social network is asymmetric, meaning that if a user A Follows B, B need not follow A back. Besides, users can set their privacy preferences such that their posted photos and videos are available only to the user's followers that requires approval from the user to be his/her follower. By default, their images and videos are public which means they are visible to anyone using Instagram app or Instagram website. Users consume photos and videos mostly by viewing a core page showing a "stream" of the latest photos and videos from all their friends, listed in reverse chronological order. They can also favourite or comment on these posts. Such actions will appear in referenced user's "Updates" page so that users can keep track of "likes" and comments about their posts. Given these functions, we regard Instagram as a kind of social awareness stream (Naaman, Boase, \& Lai 2010) like other social media platforms such as Facebook and Twitter.

While similar to Facebook in the way that users can post photos online, unlike Facebook, Instagram offers a number of special filters that allow users to change the colours and resolutions of the photographs before they post them. Although some may see a limitation of Instagram in being a mobile-only service, statistics show that mobile handsets are now the most popular form of access to social network sites (Lunden, 2014). As of February 10, 2020, 56.3\% women and $43.7 \%$ men of online adults use Instagram (Instagram Statistics, 2020). That number, however, does not include minors who anecdotally use Instagram in larger percentages.

Instagram offers a few ways to deal with cyber bullying on its app as it has a Zero Tolerance policy for cyber bullying and harassment. Where an Instagram user is being bullied, the first option for reporting such abuse is to fill out a form on the website and report the said account. It has been suggested that when cyber bullying happens, it is important to document and report the behaviour so it can be addressed. A victim of cyberbullying should not respond to nor forward cyber-bullying messages.

Instagram exists for people to self-promote and, unlike Facebook, it does not focus on social relationships. This perhaps explains why Instagram founders, Keven Systrom and Mike Krieger, created a revolutionary idea that combined increasingly available pictures with the ease of connecting with people through social media (Lagorio, 2012). The purpose of Instagram is to provide an important advantage for individuals using such a vast network to continuously learn new ideas and communicate them to an ever present community. One of the greatest advantages of having a presence on a platform, such as Instagram, is the ability to tap into the growing social media network and directly communicate with over 800 million active users from around the world. Instagram is a fantastic place for individuals to share ideas, connect with foreign worlds, increase humankind's knowledge, and increase diversity.

\section{Instagram's Anti-Bullying Restrict Feature}

The tool enables an Instagram user to restrict other accounts from posting content on and sending messages to their own account. As Instagram first explained "this Restrict is intended to limit the reach of bullies without fully blocking them, an action that may make the bullying worse". The philosophy behind shadow bans on Instagram is simple: many users, particularly teens, face bullying from peers they know in real life, such as classmates. Blocking a bully on Instagram may cause that bully to increase their torment of the user in real life, which is why many users avoid blocking them.

Instagram says Restrict addresses these concerns by taking a more nuanced approach. If someone is bullying you on the platform - posting mean comments on your photos or sending you offensive messages the new feature allows you to restrict the person's actions. Once you've restricted a user, comments on your posts from that person require your approval. You can see the comment and so can the bully, but unless you choose to release it, no one else can. Messages from the restricted user will be sent to a separate inbox, and you can choose whether or not you want to read them. If you do, the bully won't receive a read receipt.

To restrict someone, you can swipe left on the person's comment, use the privacy tab in settings or go 
directly to the profile of the account you want to restrict. Once you've restricted an Instagram user, comments on your posts from that person require your approval. You can see the comment and so can the bully, but unless you choose to release it, no one else can (Instagram, 2019). You need, as a target of bullying, to see what the actor is actually doing. The Restrict feature gives a target of bullying a bit more power over the experience.

\section{THEORETICAL FRAMEWORK}

The study was anchored on the Protection Motivation Theory and then Uses and Gratifications Theory. The premise of protection motivation theory is that individuals go through a coping assessment process to determine whether they should perform some behavior that will protect them from a particular threat. Sources of information from personal experience or an outside source influences this coping assessment. The individual then performs a threat appraisal, where he determines how severe a given threat is and how vulnerable he thinks he is to that threat. This threat appraisal conforms with the awareness, perception and use of Instagram's antibullying restrict feature among university undergraduates in South-East, Nigeria, where the student determines how well he thinks he can perform in coping with the anti-bullying restrict feature and how effective he thinks the anti-bullying restrict feature is at providing protection from the threat.

By adopting this approach, issues ranging from threats to a person's mental health to threats to a person's online activity will result to individual security behaviour as a dependent variable of interest. Therefore, by anchoring this study on the Protection Motivation theory, this research builds a newly validated instrument for measuring the online security behaviors of university undergraduates. This approach is used to address the research question; what is the perception of the undergraduates on Instagram's anti-bullying restrict feature?

\section{Uses and Gratifications}

Uses and Gratifications theory $(U \& \mathrm{G})$ which deals with the use to which different individuals put the media and the gratification they derive from such. Okorie, Ekeanyanwu and Obanua (2010) citing Chandler (1994) state that the Uses \& Gratification arose originally in the 1940s and underwent a revival in the 1970s and 1980s. The approach springs from a functionalist paradigm in the social sciences. It presents the use of media in terms of the gratification of social or psychological needs of the individual (Blumler \& Katz, 1974). The mass media compete with other sources of gratification, but gratifications can be obtained from a medium's content (e.g. watching a specific programme), from familiarity with a genre within the medium (e.g. watching soap operas), from general exposure to the medium (e.g. watching TV), and from the social context in which it is used (e.g. watching TV with the family). $\mathrm{U} \& \mathrm{G}$ theorists argue that people's needs influence how they use and respond to a medium. Zillmann (cited by McQuail 1987, p. 236) has shown the influence of mood on media choice: boredom encourages the choice of exciting content and stress encourages a choice of relaxing content.

Media theorists want the audience to believe that media serve a number of needs such as communication, social control, cohesion and cultural continuity in a society. Considering the individual, the media provide the audience with the needs of surveillance, identity formation, personal relationships, personal learning/guidance as well as diversion/ entertainment. The underpinning proposition of the functional view of the media is that the uses and gratifications needs and therefore appropriately seek the media to fulfil them. Media do not do things to people: rather, people do things with media. Rubin,(2002, p. 526) submits that the uses and gratifications study is "a psychological communication perspective" that "stresses individual use and choice". Ruggiero, $(2000$, p. 14) also argues that "as new technologies present people with more and more media choices, motivation and satisfaction become even more crucial components of audience's analysis". In the various studies, identified gratifications include surveillance, escape, arousal, sociability, instrumentality, diversion, reassurance and companionship. Thinking of motivations, gratifications seem to lead to both ritualized (passive) and instrumental (active) use of the media (Metzger \& Flanagin, 2002).

The assumption of $U \& G$ theory is that people are active in choosing and using media based on their needs (Wu, Wang, \& Tsai, 2010). For example, some people may use SNSs to meet their need for meeting new people, while others may use it to play games or to post photographs. While those needs or gratifications are not equally important for all types of media, the main ones include: diversion (escape from problems; emotional release), personal relationship (social utility of information in conversation; substitute of the media for companionship), personal identity (value reinforcement; self-understanding), and surveillance (McQuail, Blumler, \& Brown, 1972). These categories, however, were developed to understand why people use television.

Hence, the uses and gratifications approach is concerned with how people use Internet to gratify their needs as it relates with social needs and relationship. University undergraduates will apply restrict measure if it aligns with their needs and gratifications. In other words, the theory is relevant to this study since it deals with how young people could use the Internet in the practice of cyber-bullying, which may also influence the extent of self-disclosure on social media platform. They nonetheless will certainly serve the purposes of evaluating the awareness, perception and use of Instagram's anti-bullying restrict feature among university undergraduates in South-east Nigeria. 


\section{METHODOLOGY}

The study adopted the mixed method approach involving Survey and Focus Group Discussion (FGD).The combination of the two designs was aimed at exploring the strengths of the two methods - while the survey is expected to make for more empirical accuracy, the focus group discussion will provide in-depth analysis of the variables being measured. A total of 500 respondents were chosen using the multi-stage approach while 18 respondents were purposively selected for three FGD sessions; six discussants per session. The area of study was South-East Nigeria. It comprised five states of Abia, Anambra, Ebonyi, Enugu and Imo. The researcher chose three universities from the above selected states; one federal, one state and one private. Hence, NnamdiAzikiwe University, Awka, NAU (federal), Chukwuemeka Odumegwu Ojukwu University, Igbariam COOU (state) and Tansian University, Umunya (private) was selected from Anambra State, the following was selected from Abia State, Michael Okpara University, Umudike (federal) and Abia State University, Uturu (state) and Gregory University, Okigwe (private). Lastly for Enugu State, the following were selected: University of Nigeria, Nsukka, UNN (federal), Enugu State University of Science and Technology, Enugu, ESUT (state) and Godffrey Okoye University, Enugu (private).

The rationale for adopting a regional study was that such offers some reasonable degree of geographical and demographic vastness that would make for greater generalizability of the results of the study. Also the reason for studying university undergraduates notwithstanding that cyber bullying occurs outside school is due to the fact that cyber bullying is extremely harmful to students physical and mental health. First, cyber bullying often continues from school bullying, secondly it is more frequent in centers with conflictive and unsatisfactory atmosphere which the school environment provides and thirdly, it has strong effects on schooling, for instance those bullied may leave school or display worse academic performance. Also, there is a need to study older ones (youths) because previous researchers (e.g., Odora \& Matoti, 2015; Okoiye, Nwoga \& Onah, 2015; Smith et al., 2008; Walrave \& Heriman, 2011) reported that the perpetration of cyber bullying increases with age.

\section{ANALYSIS OF RESEARCH QUESTIONS}

\section{Research Question 1: To what extent are university undergraduates in South-East Nigeria aware of} Instagram's anti-bullying restrict feature?

The first research question sought to assess the level of awareness of Instagram's anti-bullying restrict feature among university undergraduates in South East Nigeria. Data collected showed that a fewer respondents had knowledge or awareness of Instagram's anti-bullying restrict feature, $65 \%$ have low awareness. The FGD data equally indicated this pattern, with the discussants exhibiting poor awareness in the majority of the discussions. Based on the foregoing, the first research question is answered by admitting that there was low awareness of Instagram's anti-bullying restrict feature among university undergraduates in the South-East Nigeria.

\section{Research Question 2: What is the perception of the undergraduates on Instagram's anti-bullying restrict} feature?

The second research question sought to find out the how the university undergraduates in South East Nigeria perceive Instagram's anti-bullying restrict feature. The result showed that the respondents are of the opinion that Instagram anti-bullying restrict feature will promote greater interaction amongst users. Focus group discussion data equally agree with this pattern as the discussants agreed that this feature is worth using if it will actually serve the purpose for which it is meant. Based on these, it could be stated, in answer to the second research question, that university undergraduates in South East Nigeria are of the opinion that Instagram's anti-bullying restrict feature will promote interaction among users.

Research Question 3: To what extent does the undergraduates use Instagram's anti-bullying feature?

The third research question sought to assess the extent to which university undergraduates in South East, Nigeria use Instagram's anti-bullying restrict feature. Results show that the respondents do not use Instagram's antibullying restrict feature. It indicates that $65 \%$ of the respondents have not used this feature. In the same vein, focus group discussion data showed this same pattern as discussants largely admitted not to have used the Instagram's anti-bullying restrict feature. Consequent upon this, it is affirmed, in answer to the third research question, that there is generally low compliance on the use of Instagram's anti-bullying restrict feature among the university undergraduates in South East.

Research Question 4: What factors influence the undergraduates' use of anti-bullying feature?

The fourth research question seek to discover the factors that influence the way South-East undergraduates' use Instagram's anti-bullying restrict feature. Data collected showed that awareness and previous experience are major factors contributing to the use of Instagram's anti-bullying restrict feature. The discussants in the focus group discussion also agreed to this. Based on the foregoing, it is admitted, in answer to the fourth research question, that awareness and previous experiences are major factors influencing the use of Instagram's antibullying restrict feature among university undergraduates in South East. 


\section{DISCUSSION OF FINDINGS}

This study showed that there was low awareness of Instagram's anti-bullying restrict feature among university undergraduates in the South-East Nigeria. Similarly, it was found that there was generally poor use of Instagram's anti-bullying feature among the undergraduates. These findings are related in that low compliance could be linked to ignorance (low awareness). Therefore, the fact that the undergraduates were largely not using the Instagram's anti-bullying restrict feature could be a product of their ignorance of this feature.

Viewed from the point of view of the protection motivation theory, the findings of this study may be an indication that the decisions people make when it comes to making use of Instagram anti-bullying restrict feature (taking security counter measures) is in direct relation to how severe they believe the consequences are should the threat materialize. This stems from an understanding of the argument that computer security is often referred to as computer health (Kearns 2006; Lacy et al. 2006), this theory displayed similar effects when applied to antibullying restrict feature. As such, adapting this to the context of dealing with cyber-bullying means that it is the confidence that a person has that he can use the Instagram's anti-bullying restrict feature to prevent a threat from manifesting into a successful attack.

Also that university undergraduates in South East Nigeria are of the opinion that Instagram's anti-bullying restrict feature will promote interaction among users. Awareness and previous experiences are major factors influencing the use of Instagram's anti-bullying restrict feature among university undergraduates in South East. This validates the position of the protection motivation theory that the individual performs a threat appraisal, where he determines how severe a given threat is, how vulnerable he thinks he is to that threat, how well he thinks he can perform in coping with the anti-bullying restrict feature and how effective he thinks the antibullying restrict feature is at providing protection from the threat. The foregoing suggests that the south east undergraduates in Nigeria might be facing the risk of social harm that might result from use of the Instagram due to lack of awareness and use. According to Sassen (2002), every new technology comes with its normative imperative, meaning that new rules and new laws would have to be adopted to protect the welfare of the individual and society. Consequently, if (as found in this study) university undergraduates' users in Nigeria are not yet at home with Instagram's anti bullying restrict feature use and so largely fail to comply with them, then they face a danger of suffering rather than benefitting from the Instagram.

\section{CONCLUSION}

From the findings of this study, it may be concluded that there is still a gap between the extent of awareness and the use of the Instagram anti-bullying restrict feature among university undergraduates in south east Nigeria. One would think that the high level of usage of Instagram especially among youths, who have been documented as the most prolific users of the net will translate to a corresponding high level of awareness regarding current features. While available data (such as Internet Worlds Stats, 2021) shows Instagram ranking the fourth most popular social media site, the findings in this study indicate that the application of this anti bullying restrict feature (with particular reference to university students in the South-East) has not been accompanied by adequate knowledge.

\section{RECOMMENDATIONS}

Based on the findings of this study, the following recommendations were made:

1. Effort should be made to educate and provide information on Instagram's anti-bullying restrict feature to young people where they can easily see or read them.

2. ICT literacy programmes in the school system of all levels (starting from primary to tertiary levels of education since computer studies are already a component of these schools' curriculum) should incorporate cyber bullying as a topic, to enlighten young people on the dangers of cyber bullying and further teach them how to protect themselves from being bullied online.

3. The Guidance and Counseling units of the universities should intensify efforts in counseling students against the negative uses of social media and other coping strategies to online bullying other than the use of technology like this.

\section{REFERENCES}

Agatston, P. W., Kowalski, R. \& Limber, S. (2007). Students perspectives on cyber bullying. Journal of Adolescent Health, 8: 9 - 16.

Almeida, A., Correia, I., Marinho, S. \& Garcia, D. (2012). Virtual but not less real: A study of cyberbullying and its relations to moral disengagement and empathy. Journal of Adolescent Health, 8: 9 - 16.

Asiedu, N. (2017). Influence of social networking sites on students' academic and social lives: eGhanaian Perspective. Library Philosophy and Practice, 6: 15-35.

Bauman, S., Toomey, R. B. \& Walker, J. L. (2013). Associations among bullying, cyberbullying, and suicide in high school students. Journal of Adolescence, 36: 341-350. 
Belsey, B. (2005). Cyberbullying: An emerging threat to the "always on" generation. http://www. cyberbullying.ca.

Beran, T. \& Li, Q. (2005). Cyber-harassment: A study of a new method for an old behavior. Journal of Educational Computing Research, 32, 265-277.

Burgess-Proctor, A., Patchin, J. \&Hinduja, S. (2006). Cyberbullying: The victimization of adolescent girls. http://www.cyberbullying.us/cyberbullying_girls_victimization.pd

Dredge, R., Gleeson, J. \& de la Piedad Garcia, X. (2014a). Cyberbullying in social networking sites: An adolescent victim's perspective. Computers in Human Behavior, 36: 13-20.

Farah, F. A. \&Yanda, U. (2015). The use of social networking among senior secondary school students in Abuja municipal area of Federal capital territory, Nigeria. Education and Practice, 6(15): 15-22.

Finkelhor, K., Mitchell, K. \&Wolak, J. (2000). Online victimization: A report on the nation's youth. Alexandria: National Center for Missing and Exploited Children

Fraser, J. (2008). Young people \& Social Networking services (overview). Retrieved January 12, 2020.

Gladden, R. M., Vivolo-Kantor, A. M., Hamburger, M. E. \& Lumpkin, C. (2014). Bullying surveillance: Uniform definitions and recommended data elements, Version 1.0. Atlanta

Hertz, M. F., Donato, I. \& Wright, J. (2013). Bullying and suicide: a public health approach. Journal of Adolescent Health, 53(1): 51-53.

Hochman, N. \& Manovich, L. (2013). Zooming into an Instagram city: Reading the local through social media. First Monday. Journal of Pyschosocial Research on Cyberspace, 4(2): 67-90.

Keith, S. \& Martin, M. E. (2005). Cyber bullying: Creating culture of respect in a cyber world. Reclaiming Children and Youth, 13(4): 224-228

Lenhart, A., Madden, M., Macgill, A. R. \& Smith, A. (2007). Teens and social media. PEW Internet \& American Life Project. Washington, DC: Pew Charitable Trusts.

McQuail, D., Blumler, J. G. \& Brown, J. (1972). The television audience: a revised perspective. In D. McQuail (Ed.), Sociology of mass communication (pp. 135e165). Middlesex, England: Penguin.

Menesini, E., Nocentini, A. \&Calussi, P. (2011). The measurement of cyberbullying: Dimensional structure and relative item severity and discrimination. Cyberpsychology, Behavior, and Social Networking, 14: $267-274$.

Messias, E., Kindrick, K. \& Castro, J. (2014). School bullying, cyberbullying, or both: Correlates of teen suicidality in the 2011 CDC youth risk behavior survey. Comprehensive Psychiatry, 55(5): 1063-1068.

Notar, C. E. \&Padgett,.S. (2013). Adults role in bullying. Universal Journal of Educational Research, 14: $294-$ 297

Okoiye, O. R. (2015). Moderating effect of cyber bullying on the psychological wellbeing of in-school adolescents in Benin Edo State Nigeria. European Journal of Sustainable Development, 4: 109-118.

Okorie, N. \&Oyedepo, T. (2011). Facebook and Online Relating: Computer Mediated romantic relationship among young Nigerians. The Nigerian Journal of Communication, 9(1): 112-129.

Okoye, O. E., Nwoga, A. N. and Onah, A. T. (2015). The moderating effect of cyber bulling on the psychological well-being of in-school adolescents in Benin Edo State Nigeria. European Journal of Sustainable Development, 4(1): 109-118.

Olumide, A. O., Adams, P. \&Amodu O. K. (2015). Prevalence and correlates of the perpetration of cyber bullying among in-school adolescents in Oyo state, Nigeria. International Journal of Adolescents Medical Health, 28(2): 183-191.

Olweus, D. (2012). Cyberbullying: An overrated phenomenon? European Journal of Developmental Psychology, 9: $520-538$

Olweus, D. (2013). School bullying: Development and some important challenges. Annual Review of Clinical Psychology, 9: 751-780.

Ovejero. A., Yubero. S., Larrañaga. E. and Moral. M. V. (2016) R. Navarro et al. (eds.), Cyberbullying Across the Globe, Springer International Publishing Switzerland 2016.

Pew Research Center. (2015). Mobile messaging and social media 2015. http://www.pewinternet.org/2015/08/19/mobile-messaging and-social-media-2015/2015 08-19_socialmedia-update_09/. Retrieved April 20, 2021.

Sheriff, S. \&Gouin, R. (2005). Cyber-dilemmas: Gendered hierarchies' free expression and cyber-safety in school. Paper presented at safety and security in a networked world: Balancing cyber-rights and responsibilities. Oxford Internet Institute Conference, on September 8, 2005, Oxford, U.K.

Slonge, R. S. \& Smith, P. K. (2008). Cyber bullying another main type of bullying. Scandinavian Journal of Psychology, 49: 147-154

Slonje, R., Smith, P. K. \&Frisén, A. (2012). Processes of cyberbullying, and feelings of remorse by bullies: A pilot study. European Journal of Developmental Psychology, 9: 244-259.

Smith, P., Mahdavi, J., Carvalho, M. \&Tippett, N. (2006). An investigation into cyberbullying, its forms, awareness and impact, and the relationship between age and gender in cyberbullying. A Report to the Anti- 
Bullying Alliance. http://www.dcsf.gov.uk/research/data/uploadfiles/ RBX03-06.pdf. Retrieved June 10, 2021.

Van den Eijnden, R. J., Vermulst, A., Van Rooij, T. \&Meerkerk, G. J. (2006). Monitor Internet. Journal of Cyberpsychology, 7: 45-49.

Vandebosch, H. \& Van Cleemput, K. (2009). Cyberbullying among youngsters: Profiles of bules and victims. New Media and Society, 11: 1349-1371.

Wade, A. \&Beran, T. (2011). Cyberbullying: The new era of bullying. Canadian. Journal of School Psychology, 26: 44-61.

Wegge, D., Vandebosch, H. \&Eggermont, S. (2013). Offline netwerken, online pesten: Eensociale network analyse van cyberpesten in de school context. Journal of Communication, 41(1), 15.

Willard, N. (2014). An educator's guide to cyber bulling and cyber threats. Retrieved from www.accem.org/pdf/cbcteducator.pdf.

Williams, K. R. \& Guerra, N. G. (2007). Prevalence and predictors of internet bullying. Journal of Adolescent Health, 41(6): 514-521 